\title{
CAPÍTULO 02: UTILIZAÇÃO DE FÓRUM VIRTUAL COMO FERRAMENTA DE ESTUDO PARA AUXÍLIO AO ENSINO REMOTO
}

\author{
CAPÍTULO 02: USO DEL FORO VIRTUAL COMO HERRAMIENTA DE ESTUDIO \\ DE AYUDA A LA EDUCACIÓN REMOTA
}

\section{CHAPTER 02: USE OF VIRTUAL FORUM AS A STUDY TOOL FOR AID TO REMOTE EDUCATION}

\author{
Stefane de Assis Orichuela ${ }^{1}$; Pedro Lucca Padilha Siqueira Ribeiro ${ }^{2}$; Victor Lucas da Costa \\ Lopes $^{3}$; Leidivânia Mendes de Araújo Melchuna ${ }^{4}$; Joel de Oliveira Santos ${ }^{5}$
}

DOI: https://doi.org/10.31692/978-65-88970-06-5.15-29

\begin{abstract}
RESUMO
Desde o início do século XXI, os cientistas vem desenvolvendo novos métodos tecnológicos que facilitam o dia a dia das pessoas, como, por exemplo, a evolução dos Smartphone, ou até o surgimento da Internet, que está cada vez mais aproximando as pessoas em longas distâncias. Diante disso, com os problemas recentes de uma nova pandemia que limitou o convívio social, ocorreu uma busca das tecnologias de informação e comunicação, em especial, na Educação. Assim, com aulas remotas e conteúdos online, o aluno tem infinidade de assuntos para explorar. No entanto, há algumas dificuldades de adaptação por parte tanto dos professores quanto dos estudantes, no último caso, uma delas é ministrar os conteúdos virtualmente, por ser algo novo, e sem a presença de um professor podem surgir dificuldades e dúvidas. Como resultado dessa situação, este artigo científico tem o objetivo de apresentar um sistema de fóruns que foi desenvolvido para que alunos possam tirar dúvidas e discutir com professores e outros alunos conteúdos abordados nas aulas online e presenciais, sendo um ambiente organizado para que os envolvidos interajam a qualquer hora. O referencial teórico que respalda este trabalho encontra-se pautado em estudos realizados sobre Tecnologias da informação e comunicação, e na utilização de fóruns virtuais. Para finalizar, vale ressaltar que o fórum pode ser utilizado por todas as instituições de ensino, facilitando também a monitoria presente nessas instituições, já que além de poder tirar dúvidas e questionar o conteúdo presente, estes registros serão salvos para que futuros estudantes que apresentem as mesmas dificuldades possam encontrar a resolução registrada por um professor ou por um aluno no fórum.
\end{abstract}

Palavras-Chave: Fórum, interatividade, Tecnologia da informação e comunicação.

\section{RESUMEN}

Desde principios del siglo XXI, los científicos han estado desarrollando nuevos métodos tecnológicos que facilitan la vida cotidiana de las personas, como la evolución de los teléfonos inteligentes, o incluso la aparición de Internet, que está uniendo cada vez más a las personas en mucho tiempo. distancias. Ante esto, con los recientes problemas de una nueva pandemia que limitaba la vida social, se buscó las tecnologías de la información y la comunicación, especialmente en Educación. Así, con clases remotas y contenido en línea, el alumno tiene multitud de materias por explorar. Sin embargo, existen algunas dificultades de adaptación tanto por parte de profesores como de alumnos, en este

\footnotetext{
${ }^{1}$ Técnico em Informática, Centro Estadual de Educação Profissional Professora Lourdinha Guerra/RN, stefaneassisori@gmail.com

${ }^{2}$ Técnico em Informática, Centro Estadual de Educação Profissional Professora Lourdinha Guerra/RN ribeiro.lucca2002@gmail.com

${ }^{3}$ Técnico em Informática, Centro Estadual de Educação Profissional Professora Lourdinha Guerra/RN, victolucs21@gmail.com

${ }^{4}$ Mestra em Letras, Centro Estadual de Educação Profissional Professora Lourdinha Guerra/RN, leidivaniamel@gmail.com

${ }^{5}$ Pós-graduando em Tecnologias Aplicadas à Educação, Centro Estadual de Educação Profissional Professora

Lourdinha Guerra/RN, joeloliveira56@gmail.com
} 
último caso una de ellas es la de impartir los contenidos de forma virtual, ya que es algo nuevo, y sin la presencia de un profesor pueden surgir dificultades y dudas. Fruto de esta situación, este artículo científico tiene como objetivo presentar un sistema de foros que se desarrolló para que los estudiantes puedan responder preguntas y discutir con los profesores y otros estudiantes los contenidos cubiertos en las clases online y presenciales, siendo un entorno organizado para que los involucrados interactúen a cualquier hora. El marco teórico que sustenta este trabajo se basa en estudios realizados en Tecnologías de la Información y las Comunicaciones, y en el uso de foros virtuales. Finalmente, cabe mencionar que el foro puede ser utilizado por todas las instituciones educativas, facilitando también el seguimiento presente en estas instituciones, ya que además de poder hacer preguntas y cuestionar el contenido actual, estos registros se guardarán para que los futuros estudiantes que presenten su información Las dificultades pueden encontrar la resolución registrada por un profesor o alumno en el foro.

Palabras Clave: Foro, interactividad, tecnologías de la información y la comunicación.

\section{ABSTRACT}

Since the beginning of the 21st century, scientists have been developing new technological methods that facilitate people's daily lives, such as the evolution of smartphones, or even the emergence of the Internet, which is increasingly bringing people together in long distances. In view of this, with the recent problems of a new pandemic that limited social life, there was a search for information and communication technologies, especially in Education. Thus, with remote classes and online content, the student has a multitude of subjects to explore. However, there are some adaptation difficulties on the part of both teachers and students, in the latter case, one of them is to teach the contents virtually, as it is something new, and without the presence of a teacher difficulties and doubts may arise. As a result of this situation, this scientific article aims to present a system of forums that was developed so that students can answer questions and discuss with teachers and other students content covered in online and face-to-face classes, being an organized environment for those involved to interact at any time. The theoretical framework that supports this work is based on studies carried out on Information and Communication Technologies, and on the use of virtual forums. Finally, it is worth mentioning that the forum can be used by all educational institutions, also facilitating the monitoring present in these institutions, since in addition to being able to ask questions and question the present content, these records will be saved so that future students who present their information difficulties can find the resolution registered by a teacher or student in the forum.

Keywords: Forum, interactivity, Information and communication technology.

\section{INTRODUÇÃO}

O fórum digital ou também conhecido como fórum de discussão, criado por John Smith em 1987, surgiu com o intuito de realizar melhores interações entre as pessoas por meio de mensagens publicadas, promovendo questões em páginas na internet que abordam um mesmo assunto. Ao passar dos anos, o fórum passou a ser mais utilizado nos meíos acadêmicos, possuindo quatro características, quais sejam: (1) livres: o professor desenvolve um fórum no ambiente virtual, a partir de um tema ou um texto de referência; (2) dirigindo: com base no fórum que o professor criou os alunos devem postar um número determinado de mensagens; (3) Permanente: o fórum estará aberto, enquanto a disciplina do curso estiver ocorrendo; (4) Tempo determinado: é determinado pelo professor a fase de funcionamento do fórum. Porquanto, conforme De Oliveira (2002, p. 5), "em termos de avanço na reflexão 
coletiva e na criação de aproximações e afinidades teóricas, o fórum é o espaço central da ação na disciplina on-line."

Destarte, com o fórum, podemos facilitar o auxílio de disciplinas virtualmente que se encontram no contexto acadêmico, oferecendo aos estudantes uma forma de receberem conhecimento e orientações tanto de um professor quanto de outros alunos, criando assim, um vínculo de interação entre a comunidade escolar. Outros benefícios que o espaço virtual oferece são o incentivo da troca de conhecimento entre alunos como também a cooperação dos professores.

Com tudo isso, graças ao espaço de fórum, a educação à distância (EAD) acaba sendo uma forma de ensino e aprendizagem mais aproveitada, visto que se utiliza da tecnologia para que professores possam virtualmente realizar aulas, atividades, fazer monitorias e ministrar conteúdos aos alunos sem haver a preocupação do desentendimento da matéria, já que o estudante poderá utilizar o fórum para tirar dúvidas. Neste contexto de pandemia, causado pela Covid-19, não é viável que ocorram aulas presenciais na escola, por conseguinte, houve um aumento expressivo na utilização de aulas remotas, a fim de buscar novas formas para realização das atividades escolares. Sendo assim, as pessoas começaram a necessitar mais ainda das tecnologias de comunicação, fazendo-as de recursos de extrema importância para o dia a dia, principalmente sendo utilizadas em instituições escolares, proporcionando aos jovens continuarem com seus estudos.

Com os problemas ocasionados pela Covid-19, as aulas presenciais se tornaram inviáveis tanto para os profissionais da educação quanto para os alunos, por esse motivo, houve a necessidade de se utilizar os ambientes virtuais de aprendizagem (AVA), facilitando assim, o compartilhamento de diversos conteúdos e disciplinas, dando um maior alcance aos estudantes, melhorando a mobilidade das aulas, atividades e trabalhos escolares realizados à distância .

Diante dos problemas citados, este artigo científico tem o propósito de apresentar um fórum digital de monitoria para que os alunos e professores possam compartilhar experiências obtidas nas aulas, podendo tirar dúvidas e resolver questões de alguns assuntos, sendo um ambiente para que alunos e professores possam interagir a qualquer momento sem se preocupar com a barreira da distância.

Portanto, o fórum poderá ser utilizado por todas as instituições de ensino, proporcionando também a monitoria escolar, já que além de tirar dúvidas e questionar conteúdos ministrados em aula, eses registros serão salvos para que futuros alunos que possivelmente tenham as mesmas dificuldades possam procurar a discussão de aprendizado 
postada anteriormente por professor ou aluno.

\section{FUNDAMENTAÇÃO TEÓRICA}

\section{UTILIZAÇÃO DO FÓRUM COMO FERRAMENTA DE ESTUDO}

Antes de tudo, é importante analisar que a ferramenta de fórum virtual pode ser utilizada no meio acadêmico, sendo um sistema remoto distribuído em hierarquias, atravessando as barreiras do tempo entre a comunidade estudantil e os professores, chegando até uma comunicação sincronizada entre ambos à distância. Exemplos que demonstram isto estão disponíveis em trabalhos de: Oliveira (2017) e Aurélio (2017), onde foi analisado o comportamento dos alunos diante de um fórum digital criado em um curso EAD de Letras; Martins (2016) e Alves (2016), onde se desenvolveu uma pesquisa exploratória para analisar a opinião dos participantes de cursos a distância, em relação a utilização do fórum como instrumento avaliativo; Gimenes et al. (2012), observaram a interação sociocultural e sua forma de aprendizagem por meio dos ambientes virtuais, e através do fórum conseguiram observar o nível de conhecimento dos alunos sobre as matérias.

Segundo Paste de Oliveira (2002 p.4), “o fórum pode ser visto como um elemento assíncrono de envio de mensagens em rede, destinadas, na maioria das vezes, a um grupo de pessoas habilitadas ao acesso das mesmas". Sendo assim, o ambiente assíncrono permite que alunos e professores aproveitem do mesmo espaço sem que ambos tenham que cumprir um horário específico de uso, proporcionando aos estudantes um maior conforto em poder se pronunciar a qualquer momento.

Além disso, a hierarquia que há dentro da plataforma, serve como um meio mais organizado de distribuir dos usuários que a utilizam, já que os fóruns digitais são organizados em Classes e Tópicos, sendo a classe um conceito geral de um tópico específico, em que cada tópico é dividido por dois tipos: Discussão e Pergunta. Nesse caso, o estudante pode escolher por criar espaços de perguntas a serem respondidas, ou abrir discussões para serem debatidas. Um exemplo que podemos citar são os fóruns presentes no Moodle (2011), que utiliza de quatro tipos diferentes de fórum atendendo aos estudantes de acordo com suas necessidades, sendo estes:

1. Fórum geral: Muito útil para grandes discussões onde há o monitoramento por parte do professor e o debate voltado a todos os alunos que se interessarem pelo assunto e querem discutir sem um prazo limite para terminar.

2. Fórum de uma única discussão simples: Utilizado para discussões curtas e com 
prazo limite.

3. Fórum em que cada usuário inicia um novo tópico: Nesse fórum, o estudante pode criar novos tópicos que incrementam debates oferecidos em discussões maiores. Esse já é um fórum mais restrito onde há um assunto que é colocado em pauta e os outros usuários só poderão criar novos tópicos relacionados ao assunto principal.

4. Fórum P e R (Pergunta e Resposta): sendo uma boa opção para os estudantes que tem alguma pergunta para ser respondida.

Com isso, o ambiente virtual proporciona de forma organizada todo um espaço dedicado para atender a dificuldade específica do aluno.

\section{AS RELAÇÕES INTERPESSOAIS NO MEIO VIRTUAL}

A interação entre alunos pode servir de grande ajuda para desenvolver o autoconhecimento, pois eles compartilham de experiências acadêmicas que já vivenciaram, tanto para ajudar um ao outro em questões como a dificuldade de entender um conteúdo, como também a capacidade de revisar e abrir a mente para o que já tenha aprendido.

\footnotetext{
"Interagir com o conhecimento e com as pessoas para aprender é fundamental. Para a transformação de um determinado grupo de informações em conhecimentos é preciso que estes sejam trabalhados, discutidos, comunicados. As trocas entre colegas, os múltiplos posicionamentos diante das informações disponíveis, os debates e as análises críticas auxiliam a sua compreensão e elaboração cognitiva. As múltiplas interações e trocas comunicativas entre parceiros do ato de aprender possibilitam que estes conhecimentos sejam permanentemente reconstruídos e reelaborados." (KENSKI, 2002:258 apud OLIVEIRA, 2002b, p. 5).
}

Pode-se concluir que, as tecnologias estão facilitando cada vez mais na aprendizagem, fazendo com que a interação remota entre os alunos sejam mais acessíveis, podendo ser dada de diversas maneiras, uma delas citada neste artigo é no fórum, visto que, essa ferramenta possui todo o ambiente adequado para atender a esse requisito.

\section{TICS NA EDUCAÇÃ̃O}

As Tecnologias da informação e comunicação (TICs) são uma excelente alternativa para se buscar uma aprendizagem em que há a comunicação entre os alunos dentro de um ambiente integrado que pode ser através de redes sociais, sites, fóruns etc..

De acordo com Thais Pacievitch (s.d) no site "InfoEscola", "tecnologia da informação e comunicação (TICs) pode ser definida como um conjunto de recursos tecnológicos, utilizados de forma integrada, com um objetivo comum". Logo, adentrar na educação pode 
servir de aliada uma vez que os alunos já têm uma intimidade e conhecimento com as tecnologias que usam.

Ademais, com o desenvolvimento da tecnologia a comunicação entre indivíduos distantes e a troca de informações deixou cada vez mais fácil a interação entre os mesmos, sem a presença física de ambos. Dentro do ambiente escolar, isso pode ser aplicado com o intuito de incentivar a comunicação entre professor e aluno, sem excluir o papel do professor, e até entre os próprios alunos a trocar informações relevantes aos assuntos passados presencialmente. Assim, como Garcia et al. (2012, p. 18) no artigo "Tecnologias de Informação e Comunicação: TICs Aplicadas à Lé” descrevem que:

\begin{abstract}
"As inovações tecnológicas acentuaram a necessidade de novas posturas no processo de ensino e aprendizagem. O professor não deveria ser, simplesmente, visto como único detentor e transmissor do conhecimento e nem o aluno como receptor passivo. O ensinar e o aprender começam a ser subsidiados (e não substituídos) pelo aparato tecnológico, que tem como uma de suas funções otimizar a construção de situações de aprendizagem significativas."
\end{abstract}

Sendo assim, é notório que as TICs vieram para mudar a forma de ensino que era praticado dentro das instituições tradicionais, trazendo de forma dinâmica e interativa, um método de ensinar que conecta tanto professor quanto aluno em um ambiente virtual integrado tanto assíncrono quanto síncrono.

\title{
METODOLOGIA
}

Esta parte do artigo é dividida em três etapas, sendo a primeira: as ferramentas e montagem do fórum, enquanto, na segunda etapa, apresentamos as partes construídas do site, e, por fim, na última etapa, compartilhamos uma pesquisa que realizamos.

\section{MONTAGEM DO FÓRUM}

Primeiramente, para a montagem do site, no qual o fórum foi providenciado, for utilizada uma pasta compactada com arquivos pré-programados (plugins) instalados no sistema, quais sejam: Social Articles, Linked Articles, Classic Editor, Two-Factor, Akismet Anti-Spam. Esses programas possuem o objetivo de adicionar funções maiores a uma aplicação, que no caso do fórum, é uma aplicação web. Graças aos plugins desenyolvidos na linguagem de programação PHP, foi possível adicionar pacotes prontos e editáveis para dar funcionamento ao que é proposto em um fórum virtual voltado à aprendizagem.

Além das tecnologias utilizadas para o funcionamento do fórum, foram aproveitados 
também junto à pasta alguns templates prontos para serem editados, feitos através da linguagem de texto HTML e de estilo CSS que foram utilizados para dar o visual e o estilo da plataforma.

Também foi utilizado o banco de dados MySQL para poder fazer o armazenamento dos dados contidos no site, sendo utilizado para armazenar os dados registrados dos alunos e professores que se cadastram no site, além das postagens e os pontos de reputação que serão apresentados ao longo deste artigo.

Por fim, foi preciso hospedar o site na internet para fazer os ajustes de edição do template e de uma breve simulação do sistema. Para isso, utilizou-se um domínio gratuíto, especificamente, o domínio “.ml” que é utilizado no Mali para poder adquirir os caracteres de identificação do site. Após isso, foi utilizada uma hospedagem gratuita no servidor Epizy para hospedar o site na internet.

\section{PROCESSO DO DESENVOLVIMENTO EXTERNO DA PLATAFORMA}

Após a montagem do site onde ficaria armazenado o fórum virtual, ainda era preciso acrescentar todos os espaços necessários dentro da plataforma, para isso, foi disponibilizado uma página específica para o administrador gerenciar todo espaço do site, criando novos fóruns dentro do sistema. Com isso, a página inicial do site foi dividida da seguinte maneira:

- Fórum Principal: Onde estarão as notícias, informações e eventos dentro do ambiente virtual.

- Fóruns das áreas: São fóruns distribuídos em áreas, onde os usuários poderão colocar conteúdos que estão de acordo com a área apresentada, sendo elas: Humanas, Linguagens, Naturezas, Matemática e a Base Técnica.

- Suporte: O fórum de suporte serve para dar suporte a algum usuário que esteja com alguma dificuldade ou dúvida em algo relacionado ao sistema.

Após essa etapa, foram organizados métodos hierárquicos para cada tipo de usuário sendo denominados de alunos e professores. Nesse caso, há objetivos específicos dentro da plataforma, como mostrado no diagrama de caso e uso abaixo: 
Figura 01: Diagrama de Caso e Uso do fórum virtual.

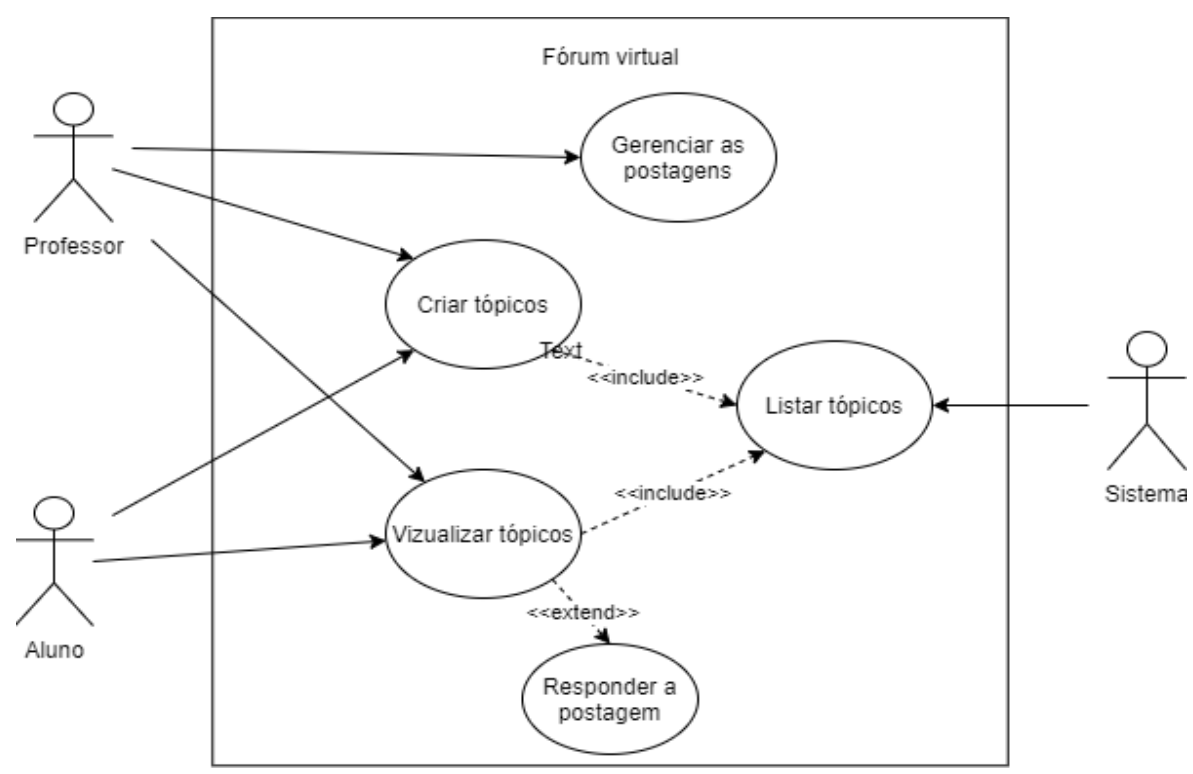

Fonte: Própria (2020).

Como mostrado na figura acima, o aluno é o agente que visualiza, responde e cria novos tópicos de fóruns, com o intuito de fazer alguma pergunta, ou iniciar um debate de um assunto específico de determinada área. Já o professor, além das mesmas opções do aluno, também pode ser o mediador, gerenciando o fluxo de mensagens que os alunos postam na plataforma, podendo assim, analisar se todas as mensagens estão de acordo com a proposta geral do fórum.

\section{PESQUISA REALIZADA}

Além da construção do fórum, fizemos também uma pesquisa quantitativa de estudo de caso com os alunos do Centro Estadual de Educação Profissional Professora Lourdinha Guerra, com o intuito de analisar o quanto os alunos da instituição tem conhecimento acerca de um fórum de discussão, analisando também as dificuldades pendentes nas disciplinas durante a educação remota, com a finalidade de prever como os alunos se comportam diante da plataforma de fórum virtual.

Para tanto, criamos um formulário no Google Forms com algumas perguntas relacionadas com nosso propósito, e compartilhamos para todos os alunos da escola, através dos líderes de sala, que por sua vez, compartilharam nos grupos de WhatsApp. 


\section{RESULTADOS E DISCUSSÃO}

\section{DEMONSTRAÇÃO DO FÓRUM}

Em relação ao desenvolvimento e descrições apresentadas sobre o fórum virtual elaborado para a instituição de ensino, é possível ter uma ideia de como exatamente funciona o fórum virtual. Para tanto, a seguir, apresentamos algumas imagens que mostram como o fórum está situado.

Figura 02: Imagem da seção de áreas na página principal do fórum virtual.

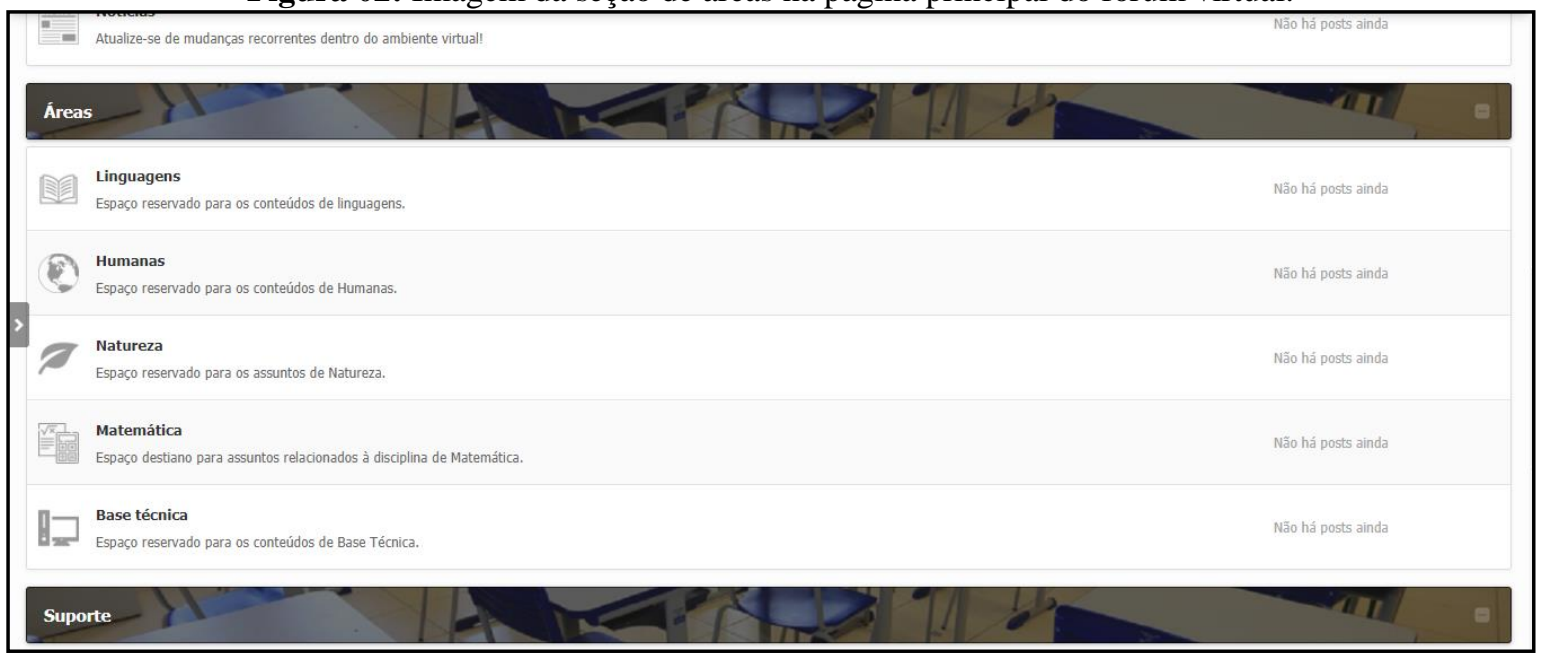

Fonte: Própria (2020)

Nessa primeira imagem, está sendo mostrado o fórum titulado “Áreas" onde está dividida entre suas respectivas camadas: "Linguagens", "Humanas", "Natureza", "Matemática", "Base técnica".

Figura 03: Página de visualização dos tópicos da área de matemática

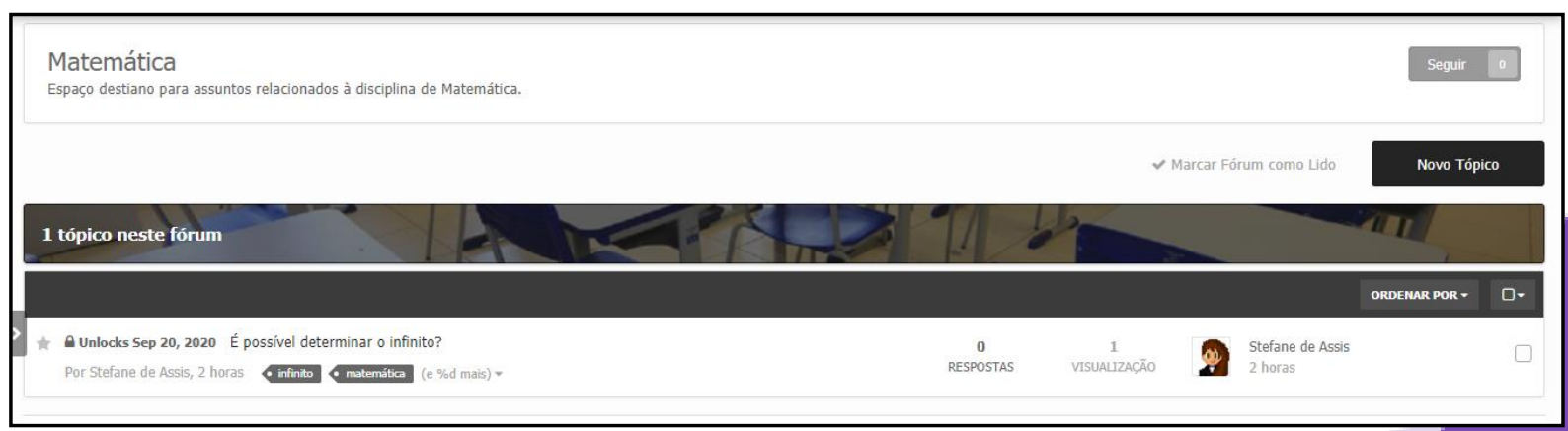

Fonte: Própria (2020).

Nessa segunda imagem, é possível observar um exemplo de postagem realizado dentro da área de "Matemática", e logo dentro da postagem, é possível ver o número de visualizações e respostas adquiridas. já acima e à direita do tópico, há um botão chamado "Novo Tópico" 
onde os alunos podem criar novas postagens dentro da área selecionada.

Figura 04: Página do usuário

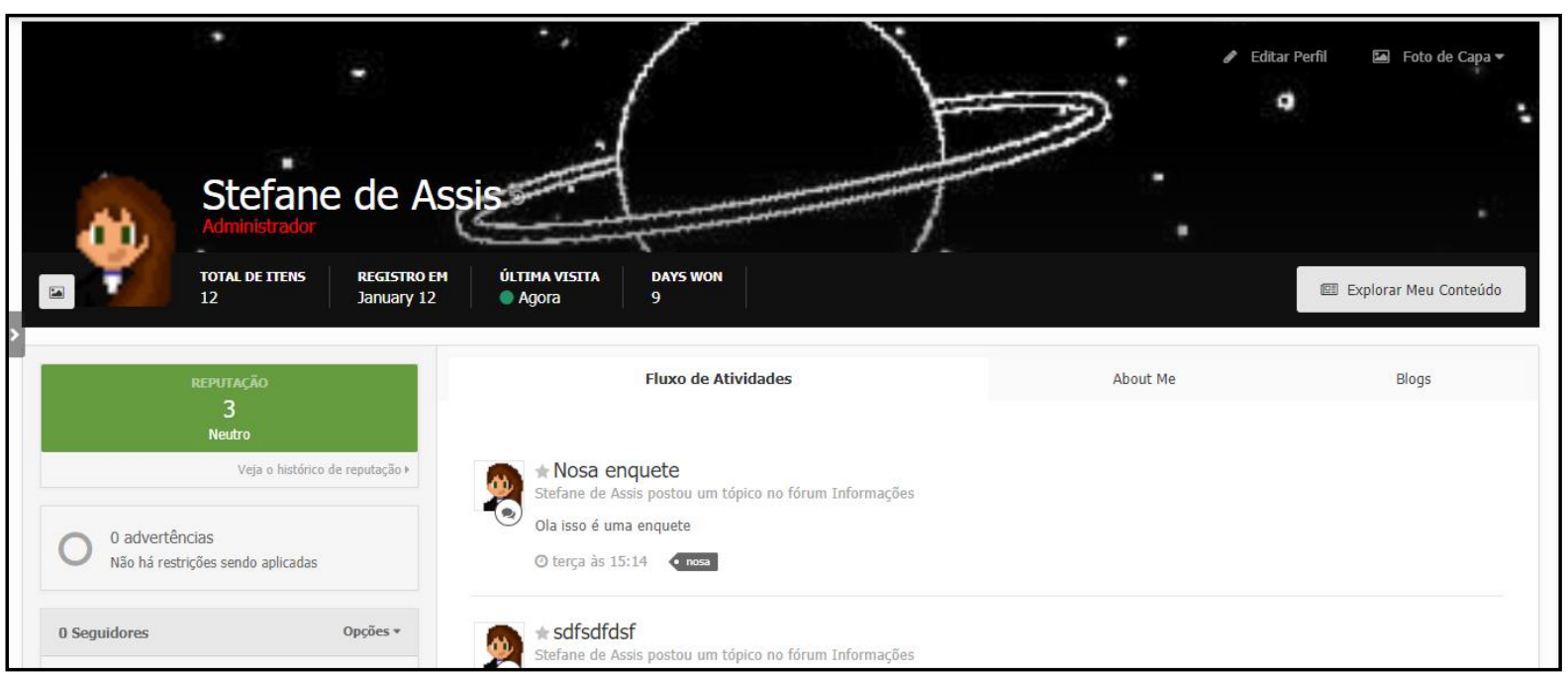

Fonte: Própria (2020).

Nessa terceira imagem, está sendo mostrada a página do perfil do usuário, distribuída pela foto do plano de fundo, que pode ser personalizada pelo usuário, o histórico de postagens, e as informações de atividades.

\section{RESULTADOS DA PESQUISA}

Em relação à pesquisa realizada com os estudantes do Centro Estadual de Educação Profissional Professora Lourdinha Guerra, que foi feita através de levantamentos de dados mediante ao questionário do Google Forms, obtivemos um total de 143 estudantes consultados, que mostrou dados relevantes comprovando a importância de um fórum virtual nas instituições de ensino. 
Figura 05: Analisando a participação dos alunos com algum fórum virtual.

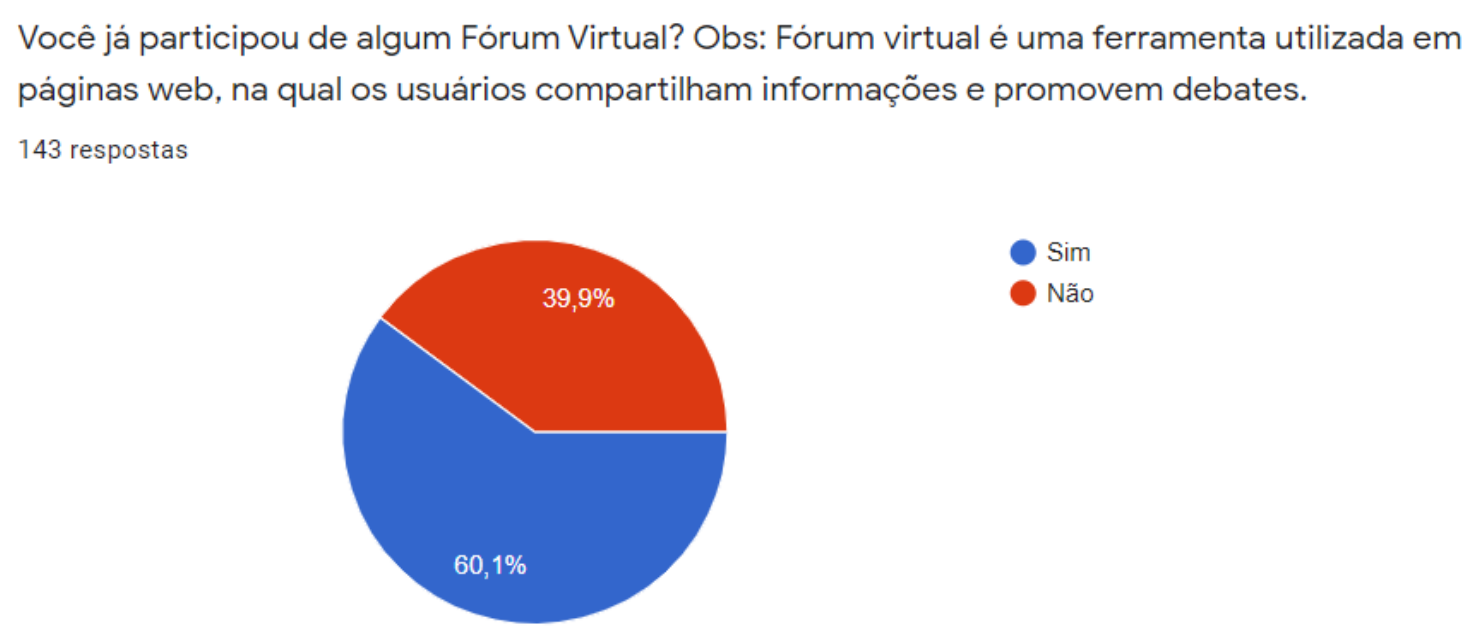

Fonte: Própria (2020).

Na figura 05, a análise de dados feita em relação à primeira pergunta trazida aos estudantes sobre o contato dos alunos com outros ambientes virtuais do tipo "fórum", mostrou-se positiva, uma vez que os resultados da pesquisa comprovaram que $60 \%$ dos 143 estudantes consultados do CEEP Professora Lourdinha Guerra apresentaram algum contato anterior com outros fóruns virtuais.

Figura 06: Analisando a participação dos alunos com seus fóruns específicos.

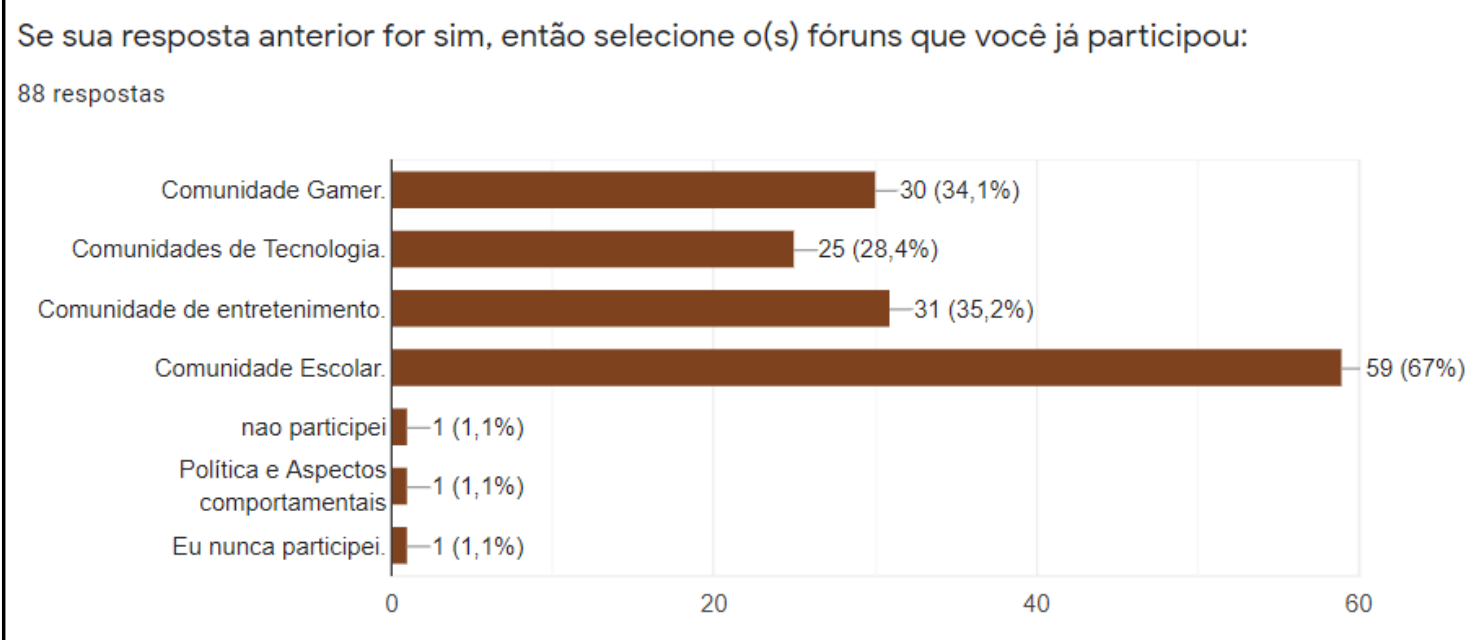

Fonte: Própria (2020).

Considerando os dados presentes na figura 06, verificamos que os alunos apresentados como participantes de fóruns virtuais tiveram que responder a outra pergunta de múltipla escolha, a qual envolvia a análise dos tipos de fórum que eles já haviam participado. Dentre os 88 alunos que responderam o "sim", 67\% já participaram de algum fórum do tipo “Comunidade Escolar". Com isso, foi possível concluir que a maior parte dos alunos já teve contato principalmente com fóruns voltados à educação, portanto não seria uma tecnologia 
desconhecida para esses estudantes.

Figura 07: Analisando o estado de aprendizagem e compreensão por parte dos estudantes em relação aos assuntos administrados remotamente no Moodle.

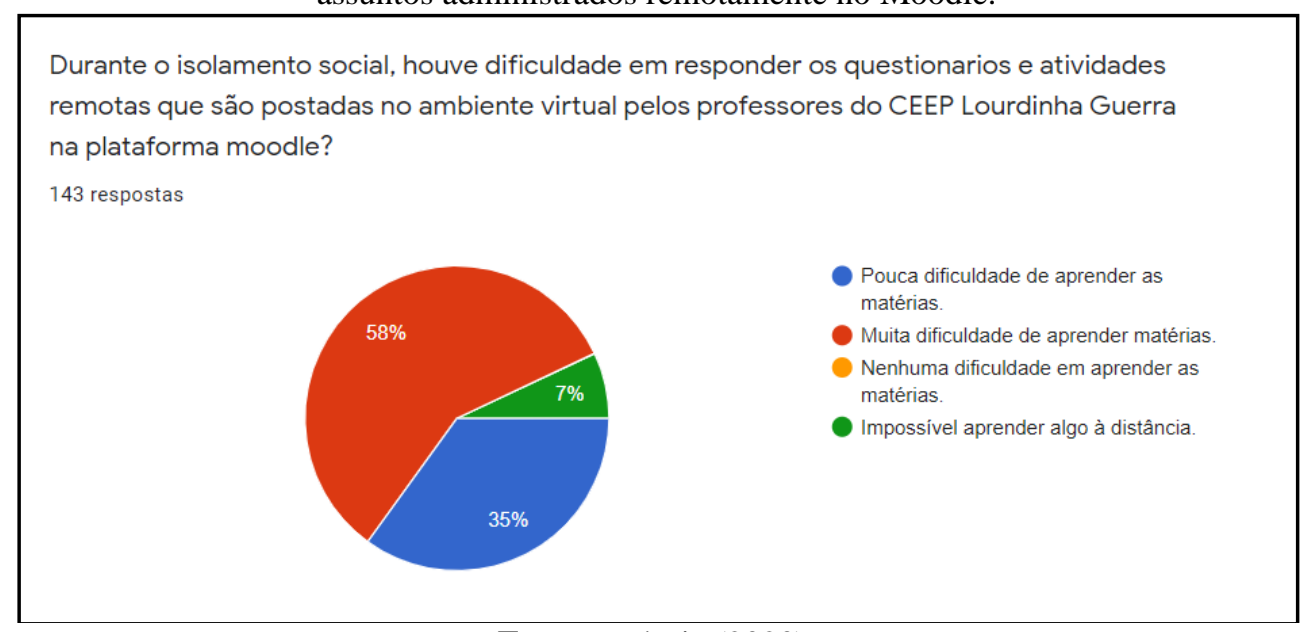

Fonte: Própria (2020).

Já nos dados presentes na figura 07, percebe-se que a maior parte dos alunos possuem problemas em responder aos questionários e aprender as disciplinas administradas remotamente, já que 58\% afirmaram ter dificuldades de aprender as matérias. Isso pode estar sendo causado pela má adaptação dos alunos ao ensino remoto durante a pandemia, uma vez que, por se tratar de uma educação diferente do que era aplicado aos alunos no ensino presencial, há muito mais dificuldade e dúvidas que surgem nas disciplinas passadas virtualmente. Portanto, necessitando de um ambiente virtual que auxilie melhor os alunos durante esse período de dificuldade e até mesmo depois para aprimorar e facilitar o aprendizado.

Figura 08: Analisando o comportamento dos estudantes diante do surgimento de uma dúvida.

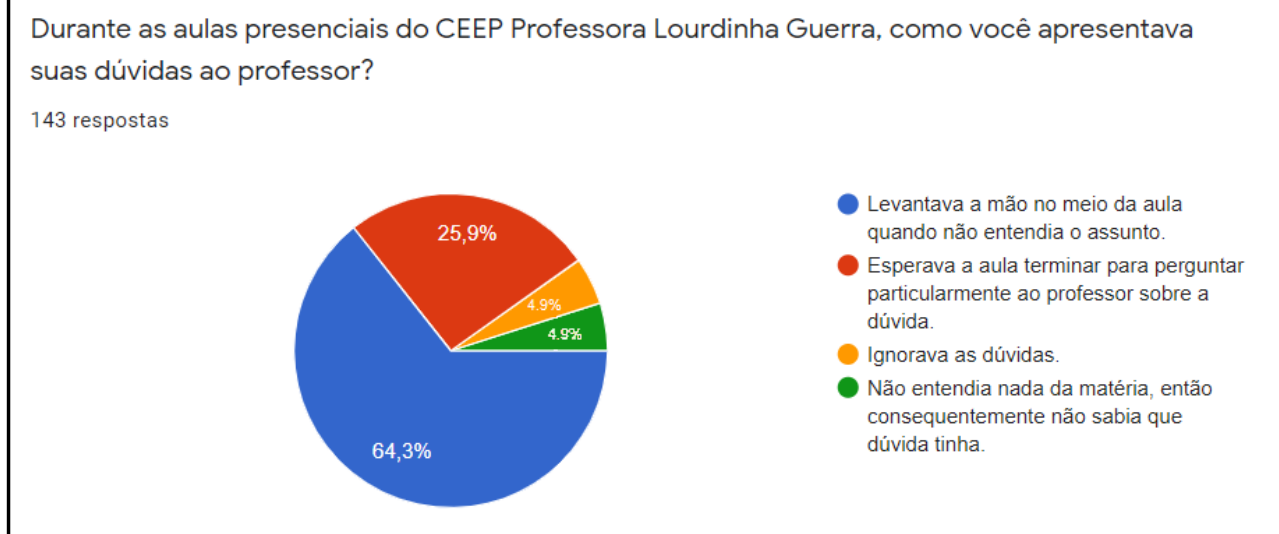

Fonte: Própria (2020).

Com base no gráfico da figura 08 , podemos perceber que a maior parte dos alunos 
levanta a mão para tirar dúvidas no meio de uma aula, o que supostamente poderia causar atrasos no conteúdo, incomodando alguns professores. Não obstante, essa atitude é importante, pois a proatividade de demonstrar dúvidas em determinado assunto torna-se positiva para alunos mais tímidos, os quais geralmente não tiram suas dúvidas em relação aos conteúdos ministrados.

Sabendo disso, se essa situação fosse trazida ao mundo virtual, as dúvidas debatidas em sala de aula poderiam estar dispostas numa forma assíncrona de mensagens salvas dentro do sistema, e a qualquer momento os alunos teriam acesso para visualizar e comentar.

Outro ponto importante, o ato da maioria dos alunos apresentarem autonomia em querer expressar suas dúvidas mostra que, não ocorre desinteresse por parte dos estudantes em demonstrar a problemática de seus entendimentos, isso se aplicada a um meio virtual, pode fazer com que alunos atuem em um ambiente único para poder tirar suas dúvidas a qualquer hora do dia, sendo respondidas até por outros alunos, já que a autonomia dentro da instituição de ensino sempre esteve presente.

\section{CONCLUSÕES}

Com base em todos os dados apresentados pela pesquisa, é possível destacar que o Fórum de discussão proporciona uma melhor interação entre os profissionais de educação e alunos nas instituições de ensino, já que além deles terem um conhecimento sobre essa plataforma, há também muitas dificuldades a serem resolvidas em relação à aprendizagem dos estudantes, principalmente diante das aulas remotas que não são tão bem aproveitadas pelos discentes, principalmente, os que estão experimentando um novo método de ensino devido ao período de distanciamento social em 2020.

Diante desse contexto, o fórum permite que, de maneira mais prática, todos possam tirar dúvidas que não foram possíveis durante as aulas, ou até mesmo tirarem dúvidas de outros estudantes, fazendo com que a aprendizagem seja socializada. Dessa forma, criando um espaço de aprendizagem colaborativa entre os acadêmicos, tornando o Fórum de discussão uma ferramenta de extrema importância para a comunidade escolar.

Por fim, vale ressaltar que, apesar de ter sido uma experiência exaustiva, o resultado foi muito gratificante, trazendo muita experiência para nosso desenvolvimento acadêmico e técnico em nosso curso de Informática. Desse modo, acreditamos que a divulgação deste trabalho nos proporcionará muitos caminhos, visto que somos iniciantes na área de desenvolvimento e projetos. 


\section{REFERÊNCIAS}

ALVES, Lucicleide; MARTINS, Alexandra. O Fórum de Discussão como Instrumento Avaliativo de Aprendizagem. SENAC de Brasília; Universidade Católica de Brasília, Porto Alegre, 2016.

AURÉLIO, Renato; OLIVEIRA, Jossiane. Utilização do fórum enquanto ferramenta pedagógica digital em um curso de letras - Português (EAD). Curso de Especialização em Linguísticas Aplicada ao Ensino de Língua Inglesa - UNEB, Bahia, 2017.

DE OLIVEIRA, Gerson Paste. O fórum em um ambiente virtual de aprendizado colaborativo. São Paulo: Associação Brasileira de Educação a Distância. 2011. Acesso em, v. 14, 2018.

GARCIA, Daniela; MESSIAS, Rozana; NORTE, Mariângela. Tecnologias de informação e comunicação: TICs aplicadas à Le. Curso de especialização para o quadro do Magistério da SEESP, São Paulo, p.08-57, 2012.

GIMENES, Solange; SANTOS, Washington; TOCZEK, Jonathan. O fórum como ferramenta mediadora de aprendizagem: Aprendizagem na educação à distância: Desafios, estratégias e dificuldades. Universidade Federal de São Carlos - UFSCar, São Paulo, 2012.

IZARIAS, Nilma; NUNES, Carolina; SANTOS, Simone. O fórum virtual e suas potencialidades para a interação em ambientes educativos virtuais. XV Congresso Brasileiro de Ensino Superior à distância, IV Congresso Internacional de Educação Superior à Distância, esud, Natal, 2018.

MOODLE. Fóruns, 2011. Documentation. Disponível em: <https://docs.moodle.org/all/pt_br/F\%C3\%B3runs >. Acesso em: 28 de Jul. de 2020.

NOBRE, Artur; NUNES, Isabel; OLIVEIRA, Juliana; PAIVA, Maria; RABELO, Danieli; ROCHA, Stênio. Utilização do fórum como ferramenta colaborativa na EAD. Programa de Pós-Graduação em Inovação em Tecnologias Educacionais;

O QUE é AVA?. edools: Tudo que você precisa saber sobre ensino online, [s.d]. Perguntas Frequentes. Disponível em: 〈https://www.edools.com/faq/o-que-e-ava/>. Acesso em: 28 de Jul. de 2020.

O QUE é EAD?. edools: Tudo que você precisa saber sobre ensino online, [s.d]. Perguntas Frequentes. Disponível em: 〈https://www.edools.com/faq/o-que-e-ead/>. Acesso em: 28 de Jul. de 2020.

O QUE é Monitoria?. Proenem: Atendimento para o enem, [s.d.]. Perguntas frequentes. Disponível em: <https://atendimento.proenem.com.br/hc/pt-br/articles/360001438373-O-queé-Monit\%20oria->. Acesso em: 28 de Jul. de 2020.

POR causa do Coronavírus, aulas EAD têm crescimento significativo. Diário de Goiás, Goiânia, 20 de Mar. de 2020. Disponível em: <https://abmes.org.br/noticias/de

Acesso em: 28 de Jul. de 2020. 
TECNOLOGIA e informação da comunicação. InfoEscola: Navegando e aprendendo, [s.d]. Disponível em: <https://www.infoescola.com/informatica/tecnologia-da-informacao-ecomunicacao/>. Acesso em: 04 de Set. de 2020.

VIEIRA, Rosângela Souza. O Papel das tecnologias da informação e comunicação informação e comunicação na educação à distância: um estudo sobre a percepção da educação à distância o professor/tutor. Formoso-Ba: Universidade Federal do Vale do São Francisco (UNIVASF), v. 10, 2011, pp.66-72 